\title{
Manganese Removal from Liquid Nickel by Hydrogen Plasma Arc Melting
}

\author{
Xiliang Guo ${ }^{1,2}$, Jianbo Yu ${ }^{1,2, *}$, Yuan Hou ${ }^{1,2}$, Yujia Zhang ${ }^{1,2}$, Jiang Wang ${ }^{1,2}$, Xia Li ${ }^{1,2}$, \\ Hanlin Liao $^{3}$ and Zhongming Ren ${ }^{1,2, *}$ \\ 1 State Key Laboratory of Advanced Special Steel, Shanghai University, Shanghai 200444, China; \\ xlguo@shu.edu.cn (X.G.); houyuan@i.shu.edu.cn (Y.H.); yujzhang@shu.edu.cn (Y.Z.); \\ jiangwang@i.shu.edu.cn (J.W.); xiali@shu.edu.cn (X.L.) \\ 2 School of Material Science and Engineering, Shanghai University, Shanghai 200444, China \\ 3 ICB UMR 6303, CNRS, University Bourgogne Franche-Comté, UTBM, F-90010 Belfort, France; \\ hanlin.liao@utbm.fr \\ * Correspondence: jbyu@shu.edu.cn (J.Y.); renzm2201@163.com (Z.R.); Tel.: +86-21-5633-1102 (Z.R.); \\ Fax: +86-21-5633-1102 (Z.R.)
}

Received: 17 November 2018; Accepted: 19 December 2018; Published: 22 December 2018

\begin{abstract}
In this work, the removal of manganese from nickel melts by Ar and (10\%, 20\% and $40 \%) \mathrm{H}_{2}$ plasma arc melting under various pressures $(0.01-0.02,0.04-0.05$ and $0.09-0.1 \mathrm{MPa})$ was investigated experimentally. The results show that only a slight reduction in the manganese content is obtained by Ar plasma arc melting (PAM). By contrast, the manganese content of liquid nickel decreases noticeably upon the addition of hydrogen to plasma gas, and the rate of manganese removal increases with increasing hydrogen volume fraction. In addition, the reduction in the pressure enhances the efficiency of manganese removal from liquid nickel by hydrogen plasma arc melting (HPAM). The process of manganese removal by HPAM was found to obey a first-order rate law. From kinetic analysis, the rate of reduction in the manganese content increases proportionally to the $0.73-0.75$ th power of the hydrogen volume fraction in the plasma gas. However, the rate of the manganese content reduction increases proportionally to approximately 0.88 th power of $\% \mathrm{H}_{2}$ in the plasma gas for the initial manganese content of 0.89 mass $\%$, which is slightly higher than that for the initial manganese concentration of 0.45 mass $\%$. Thermodynamic analysis indicates that the volatilization of manganese benefits from negative pressure and the presence of active hydrogen atoms that act as the transfer media of the metal vapor in the gas boundary layer.
\end{abstract}

Keywords: manganese removal; nickel melt; hydrogen plasma arc melting; kinetic; thermodynamic

\section{Introduction}

The demand for high-purity nickel has been increasing in recent years due to its excellent mechanical properties. Nickel is a key element in high-temperature stress-resistant and corrosion-resistant superalloys used in the aerospace industry [1]. In addition, pure nickel has also been applied in electrodeposited Ni-Co coating materials [2], biomaterials [3], and low-expansion alloys [4] and is a potential tool material for the thixoforming of steels [5]. High-purity nickel is also a key material in the production of hydrogen-generation catalysts and other chemicals [6]. Obviously, the impurities in the metal are harmful to its properties. Therefore, removal of impurities from nickel has always been a focus of research.

To date, non-metallic impurities have been eliminated by various agents, such as $\mathrm{Si}, \mathrm{Hf}, \mathrm{Y}, \mathrm{Al}$, $\mathrm{Mg}$, and $\mathrm{Zr}$ [7-12]. The metallic impurities have been easily removed by electric beam melting (EBM) through its conditions of high vacuum and high temperature during melting [13]. However, its 
significant weight loss and high cost have hindered the wide use of EBM. Recently, hydrogen plasma arc melting (HPAM) was developed for refining active metals such as $\mathrm{Hf}, \mathrm{Cr}, \mathrm{Zr}, \mathrm{Nb}, \mathrm{Ti}, \mathrm{Tb}$, and Gd [14-22]. It was found that hydrogen in the plasma could increase the efficiency of metallic impurity removal. However, few investigations have been done on the purification of nickel by HPAM.

In this work, the effect of the hydrogen content in the plasma gas, melting pressure, and initial manganese content on the removal of a typical metallic impurity manganese by HPAM has been studied systematically. The kinetics and thermodynamics of this process were examined to investigate the mechanism of the manganese removal by HPAM.

\section{Experimental Sections}

As shown in Figure 1, the plasma arc furnace with a transferred arc type plasma torch (Zhen Bang Areospace Precision Machinery Co. Ltd, Beijing, China) was used in the present work. A stable non-transfer arc was generated by the pilot arc power source. The D.C. power (transformed from a 3-phase A.C. power) was applied to obtain the transfer arc. The plasma arc power used for melting was $6 \mathrm{~kW}$. A water-cooled Cu crucible was used as the anode. The cathode was made from tungsten and was placed in the plasma torch. The raw nickel ingot (containing approximately 0.45 mass $\%$ and 0.89 mass $\% \mathrm{Mn}$, approximately $25 \mathrm{~g}$ ) was loaded on the water-cooled Cu crucible of $40 \mathrm{~mm}$ in diameter and $6 \mathrm{~mm}$ in depth. To eliminate the residual gas, the plasma arc furnace was evacuated to $6 \times 10^{-3} \mathrm{~Pa}$ and flushed with high-purity Ar gas. The high-purity $\mathrm{Ar}$ and $\mathrm{H}_{2}$ plasma gas were mixed and introduced into the plasma torch. The flow rate of the plasma gas was constantly $5 \mathrm{~L} / \mathrm{min}$. The volume fraction of $\mathrm{H}_{2}$ in the plasma gas was $10 \%, 20 \%$ and $40 \%$, respectively. For uniform refinement, the sample was melted again after being turned over. The total melting times for each specimen were 30,60 and $120 \mathrm{~min}$, respectively. The melting process was conducted under the pressures of $0.01-0.02,0.04-0.05$, and $0.09-0.1 \mathrm{MPa}$, respectively. The amount of manganese was determined using an optical emission spectrometer (OES, SPECTRO, Kleve, Germany). All specimens were grinded and polished before analyzed by OES.

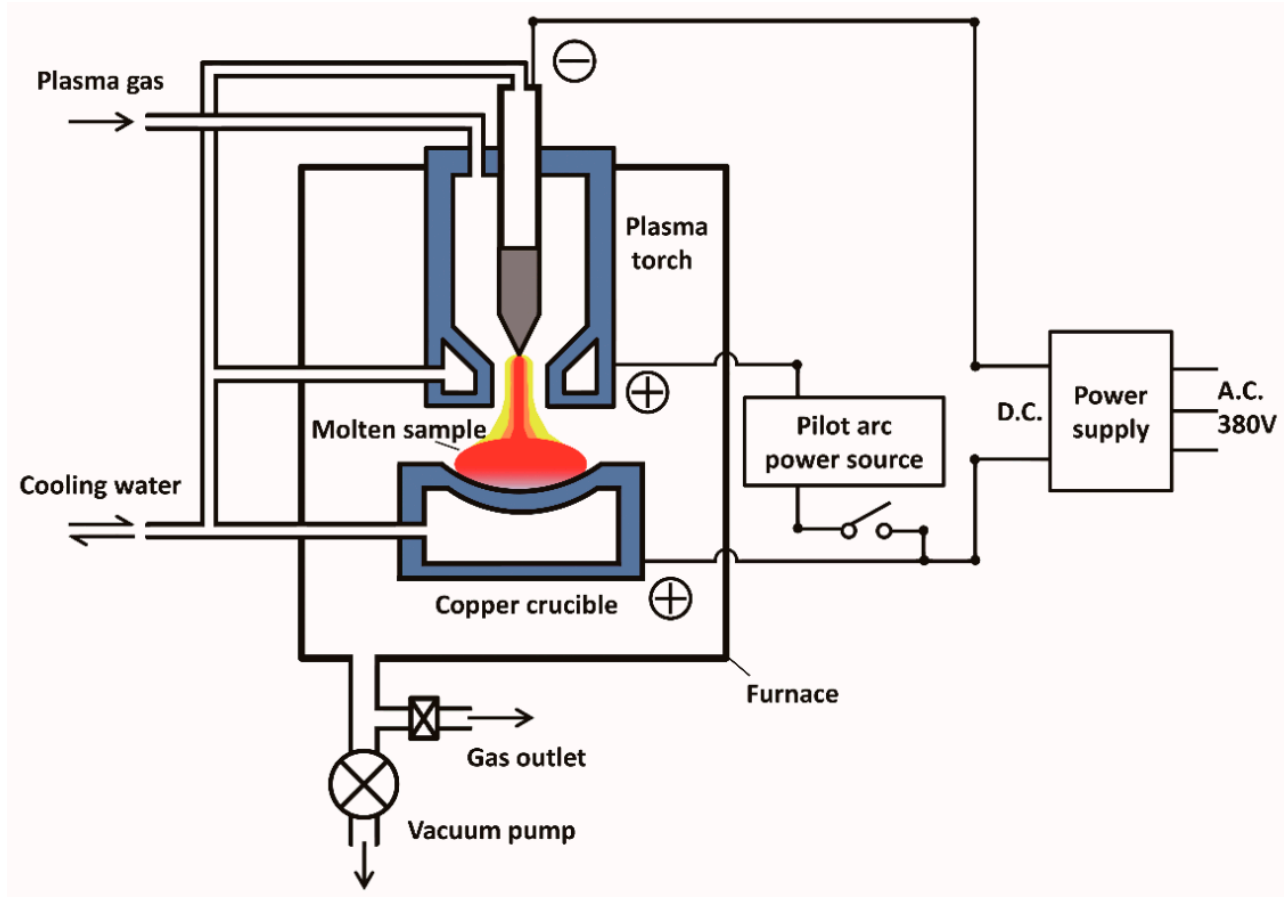

Figure 1. Schematic diagram of plasma arc furnace. 


\section{Results and discussion}

The changes in the manganese concentration in the liquid nickel by argon plasma arc melting (PAM) and hydrogen plasma arc melting (HPAM) under pressure of 0.04-0.05 and 0.09-0.1 MPa are illustrated in Figure 2 as a function of melting time. For the pressure of 0.09-0.1 MPa, the manganese content decreased slowly after PAM. However, the manganese concentration decreased obviously with the addition of hydrogen in the plasma gas, in Figure 2. After 120 min of HPAM with addition of $10 \%, 20 \%$ and $40 \% \mathrm{H}_{2}$ in plasma gas, the manganese content of decrease from about $0.45 \%$ to $0.32 \%, 0.28 \%$, and $0.16 \%$, respectively. On the other hand, a similar phenomenon about the manganese concentration reduction after HPAM was found under the pressure of $0.04-0.05 \mathrm{MPa}$. A slight reduction of manganese content was observed when the plasma gas consisted of argon only. The manganese concentration decreased significantly by the adding of hydrogen in the plasma gas. For the proportion of hydrogen at $10 \%, 20 \%$, and $40 \%$, after 120 min melting of HPAM, the manganese content of decrease from about $0.45 \%$ to $0.25 \%, 0.14 \%$, and $0.09 \%$, respectively. Moreover, the decrease rate in manganese concentration increased with the hydrogen proportion in the plasma gas.

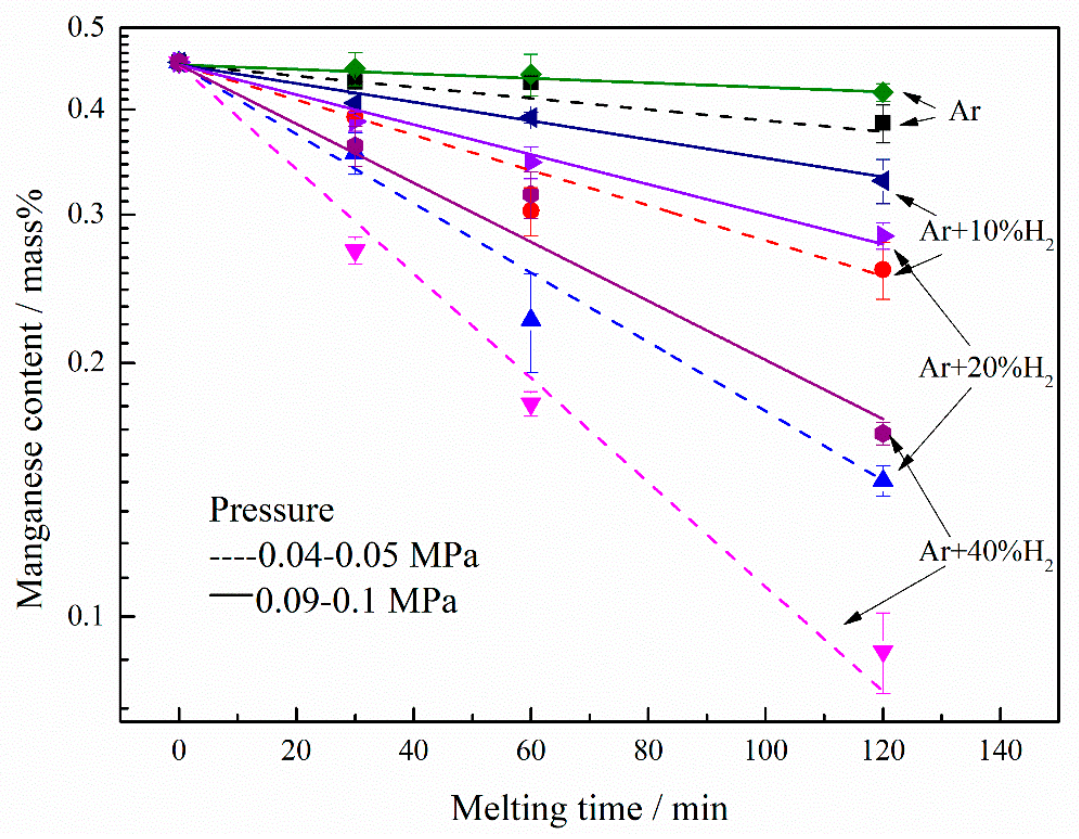

Figure 2. Change in the manganese content of liquid nickel during HPAM at 0.04-0.05 and 0.09-0.1 MPa.

Furthermore, the relationship between the logarithm of the manganese content and the melting time is almost linear, indicating that the process of manganese removal from liquid nickel by HPAM obeys a first-order rate law. There is a slight scattering around the straight lines. However, the data point with error bar was almost on the line. The apparent manganese reduction rate constant $k_{M n}$ and the standard error of the lines of best fitting were listed in Table 1. It indicated that the standard error is much smaller than the manganese reduction rate constant. Therefore, the standard error can be ignored. It suggests that minor composition segregation occurs in the samples. It is clearly observed that the slope of the solid line is smaller than that of the dashed line, which means that the rate of manganese removal under the pressure of $0.04-0.05 \mathrm{MPa}$ is larger than that under the pressure of 0.09-0.1 MPa. 
Table 1. The manganese reduction rate constant and its corresponding standard error.

\begin{tabular}{ccccc}
\hline Plasma gas & $\boldsymbol{k}_{\mathbf{M} \boldsymbol{n}}$ under 0.09-0.1 MPa & Standard Error & $\boldsymbol{k}_{\mathbf{M} \boldsymbol{n}}$ under 0.04-0.05 MPa & Standard Error \\
\hline $\mathrm{Ar}$ & $6.24 \times 10^{-4}$ & $2.0 \times 10^{-5}$ & $1.20 \times 10^{-3}$ & $5.4 \times 10^{-5}$ \\
$\mathrm{Ar}-10 \% \mathrm{H}_{2}$ & $2.74 \times 10^{-3}$ & $5.6 \times 10^{-5}$ & $4.97 \times 10^{-3}$ & $2.1 \times 10^{-4}$ \\
$\mathrm{Ar}-20 \% \mathrm{H}_{2}$ & $4.08 \times 10^{-3}$ & $8.3 \times 10^{-5}$ & $9.56 \times 10^{-3}$ & $2.7 \times 10^{-4}$ \\
$\mathrm{Ar}-40 \% \mathrm{H}_{2}$ & $7.74 \times 10^{-3}$ & $2.2 \times 10^{-4}$ & $1.37 \times 10^{-2}$ & $3.3 \times 10^{-4}$ \\
\hline
\end{tabular}

The process of manganese removal from the liquid nickel can be expressed by Equation (1), where [\%Mn] and $k_{M n}$ are the manganese concentration in mass $\%$ and the apparent manganese reduction rate constant, respectively. Integration of Equation (1) gives Equation (2), in which [\%Mn $]_{0}$ and $[\% M n]_{t}$ are the manganese concentrations at $t=0$ and $t=\mathrm{t}$, respectively. Based on Equation (2), the values of $k_{M n}$ at the respective hydrogen contents in the plasma gas can be derived from the slopes of the straight lines in Figure 2. On the one hand, under the pressure of 0.09-0.1 MPa, for the hydrogen volume fraction of $10 \%, 20 \%$ and $40 \%$, the apparent manganese reduction rate constants were $2.74 \times 10^{-3}, 4.08 \times 10^{-3}$ and $7.74 \times 10^{-3} \mathrm{~min}^{-1}$, respectively. On the other hand, under the pressure of $0.04-0.05 \mathrm{MPa}$, the apparent manganese reduction rate constants were $4.97 \times 10^{-3}, 9.56 \times 10^{-3}$, and $1.37 \times 10^{-2} \mathrm{~min}^{-1}$, corresponding to the hydrogen fractions of $10 \%, 20 \%$, and $40 \%$, respectively.

$$
\begin{gathered}
-d[\% M n] / d t=K_{M n} \cdot[\% M n] \\
\lg [\% M n]_{0}-\lg [\% M n]_{t}=K_{m n} \cdot t / 2.303
\end{gathered}
$$

As described in Figure 3, the apparent reduction rate constant $k_{M n}$ is plotted against the hydrogen volume fraction $\% \mathrm{H}_{2}$ on the log-log scale. It is found that a good linear relationship exists between $k_{\mathrm{Mn}}$ and $\% \mathrm{H}_{2}$. According to the calculated results, for the pressure of $0.04-0.05 \mathrm{MPa}$, the slope of the plot of $k_{M n}$ against $\% \mathrm{H}_{2}$ is approximately 0.73 , as expressed in Equations (3) and (3a). Equation (4) is obtained by substituting Equation (3a) into Equation (1). Equation (4) indicates that the reduction rate of manganese increases linearly to approximately 0.73 th power of $\% \mathrm{H}_{2}$ in the plasma gas.

$$
\begin{gathered}
K_{M n} \propto\left(\% \mathrm{H}_{2}\right)^{0.73} \\
K_{M n}=K_{M n}{ }^{\prime}\left(\% \mathrm{H}_{2}\right)^{0.73} \\
-d[\% M n] / d t=K_{m n}{ }^{\prime}\left(\% \mathrm{H}_{2}\right)^{0.73} \cdot[\% \mathrm{Mn}]
\end{gathered}
$$

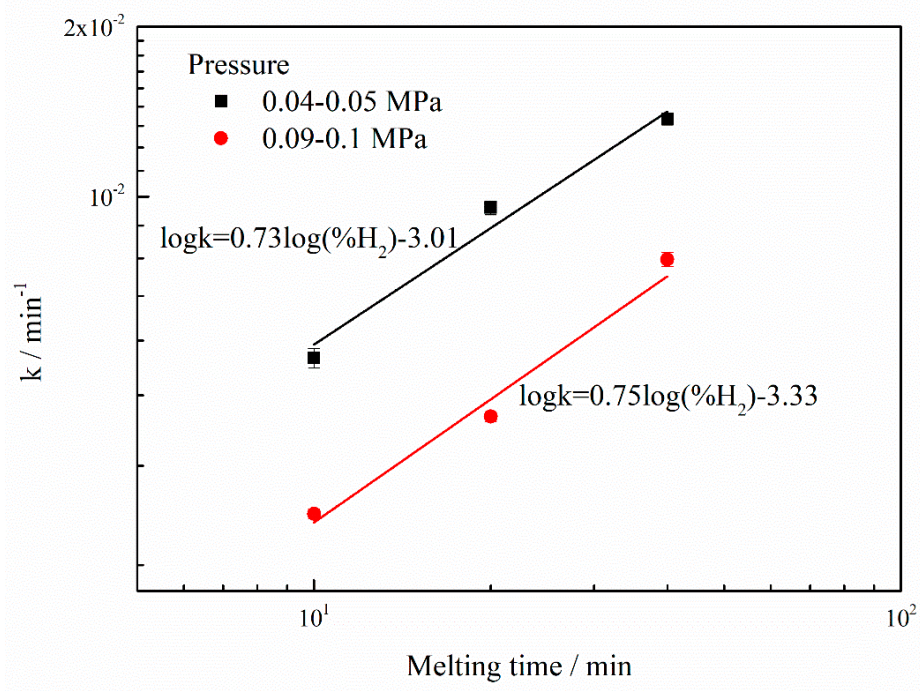

Figure 3. Dependence of the apparent manganese reduction rate constant $\left(k_{M n}\right)$ on the hydrogen volume proportion $\left(\% \mathrm{H}_{2}\right)$. 
On the other hand, the reduction rate under the pressure of $0.09-0.1 \mathrm{MPa}$ is observed to increase proportionally to approximately 0.75 th power of the hydrogen fraction. This suggests that there is no significant difference between the slopes in Figure 3 for the pressures of 0.04-0.05 and 0.09-0.1 MPa.

According to the $k_{M n}$ values under different pressures and various hydrogen fractions in the plasma gas, the manganese removal rate increases with the augment of hydrogen content in the plasma gas. In addition, the $k_{M n}$ values under the lower pressure of 0.04-0.05 MPa were higher than those for the pressure 0.09-0.1 MPa. This indicates that dropping pressure is a beneficial method for removing manganese from the nickel melt. Therefore, under the pressure of 0.01-0.02 $\mathrm{MPa}$, the experiments for manganese removal from liquid nickel by PAM and HPAM were performed. However, it was found that the transferred plasma arc was unstable when hydrogen was added to the plasma gas at the pressure of 0.01-0.02 MPa. The results after melting for $60 \mathrm{~min}$ by PAM are shown in Figure 4, and it is observed that the manganese concentration clearly decreases in pressure.

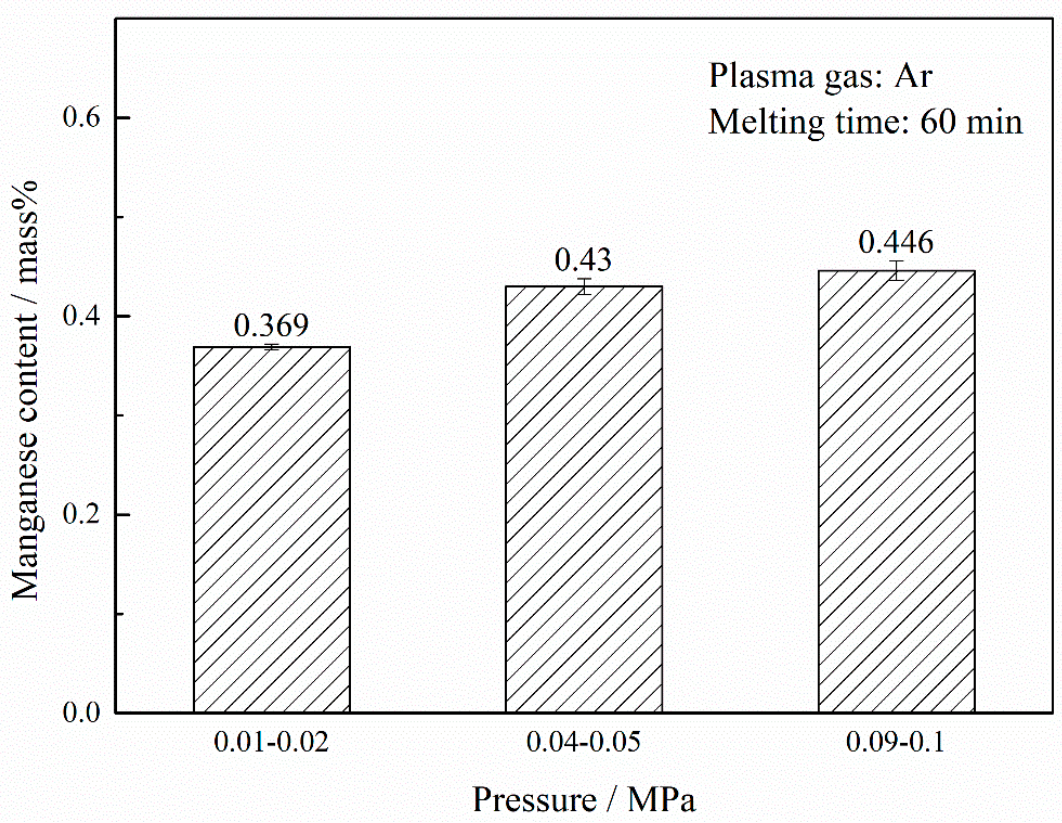

Figure 4. Manganese content after PAM under different pressures.

With the different initial manganese concentrations, the changes in the manganese content in the nickel melt during PAM and HPAM as a function of the melting time were illustrated in Figure 5. Be the same as shown in Figure 1, the manganese content declined slightly after PAM and clearly decreased with the addition of hydrogen to the plasma gas. Furthermore, the rates of manganese reduction were calculated, according to Equation (2) and based on the slopes of the fitting lines in Figure 5. For the initial manganese content of 0.89 mass $\%$ and the volume fraction of hydrogen of $10 \%$, $20 \%$ and $40 \%$, the apparent manganese content reduction rate constants were $1.96 \times 10^{-3}, 3.59 \times 10^{-3}$ and $6.63 \times 10^{-3} \mathrm{~min}^{-1}$, respectively. On the other hand, for the initial manganese concentration of 0.45 mass $\%$, the apparent manganese content reduction rate constants were $4.97 \times 10^{-3}, 9.56 \times 10^{-3}$ and $1.37 \times 10^{-2} \mathrm{~min}^{-1}$, corresponding to the hydrogen fraction of $10 \%, 20 \%$ and $40 \%$, respectively. This shows that the manganese content reduction rate increases with the decrease in the initial manganese content. Figure 6 shows the apparent reduction rate constant $k_{M n}$, and $k_{M n}$ plotted against the hydrogen volume fraction $\% \mathrm{H}_{2}$ on the log-log scale. It is observed that there is a good linear relationship between $k_{\mathrm{Mn}}$ and $\% \mathrm{H}_{2}$. Under the pressure of $0.04-0.05 \mathrm{MPa}$, for the initial manganese content of 0.45 mass $\%$, the slope of the plot of $k_{M n}$ versus $\% H_{2}$ is approximately 0.73 . On the other hand, the slope of $k_{M n}$ against $\% \mathrm{H}_{2}$ is about 0.88 for the manganese content of 0.89 mass \%. This suggests that the manganese content reduction rate increases proportionally to 0.73 th power of the 
$\% \mathrm{H}_{2}$ in the plasma gas for the initial manganese content of $0.45 \%$, which is a slightly lower than that for the initial manganese concentration of $0.89 \%$.

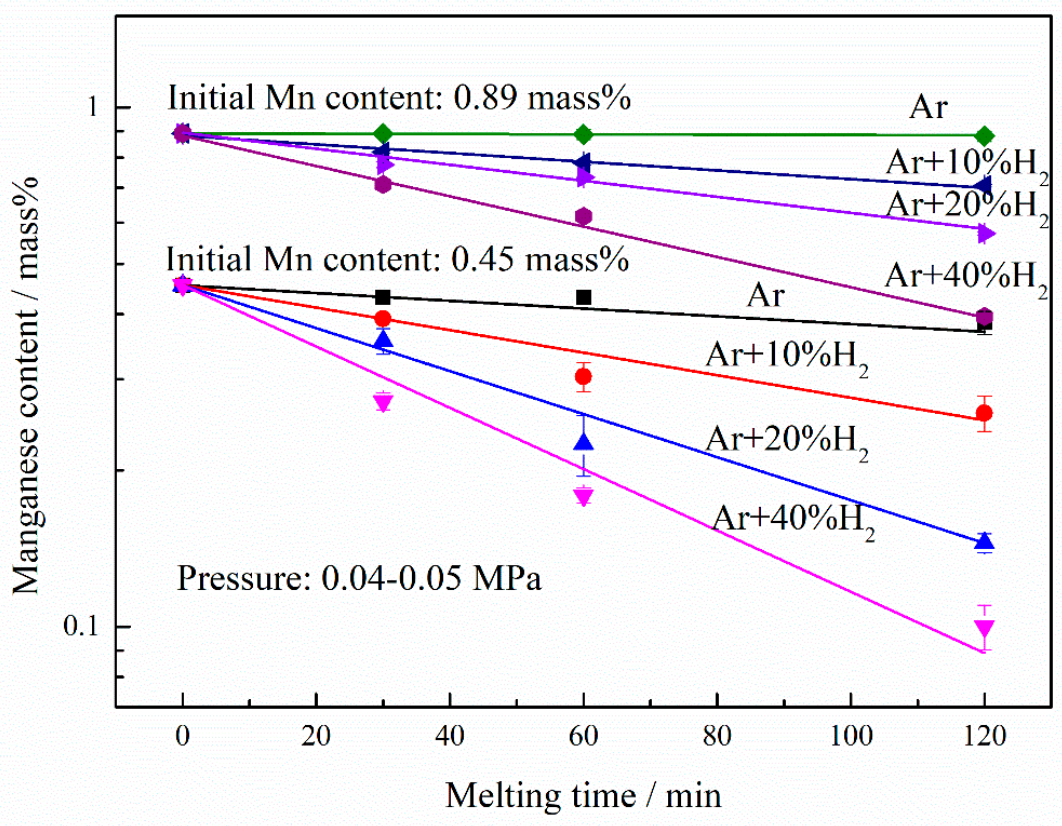

Figure 5. Change in the manganese content of liquid nickel during HPAM with different initial manganese contents ( 0.89 mass $\%$ and 0.45 mass $\%$ ).

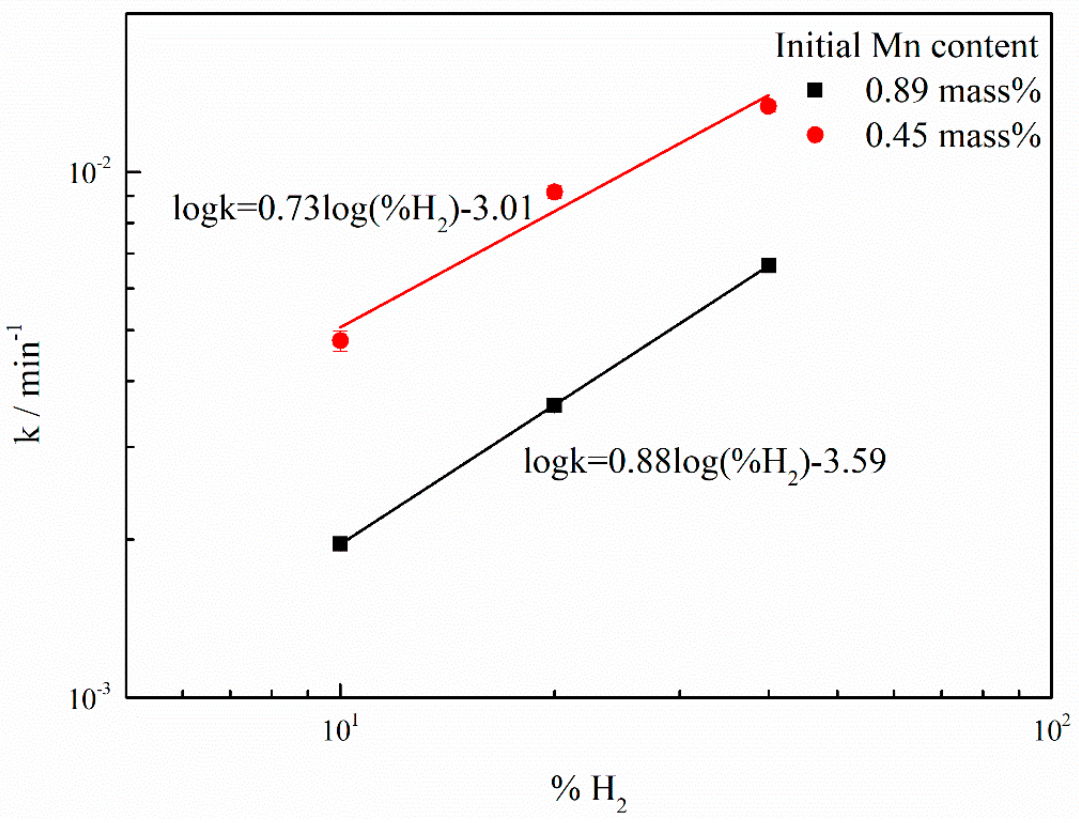

Figure 6. Dependence of the apparent manganese content reduction rate constant $\left(k_{M n}\right)$ on the hydrogen volume fraction $\left(\% \mathrm{H}_{2}\right)$ for different initial manganese contents $(0.89$ mass $\%$ and 0.45 mass $\%)$.

Based on the above mentioned results, HPAM was confirmed to be an efficient method for removing metallic impurities. The beneficial effect for manganese removal from the nickel melt is closely related to the vapor pressures of manganese and nickel. The thermochemical equations of manganese and nickel are described in Equations (5)-(7) [23]. According to the equations, the vapor pressures of manganese and nickel as a function of temperature are shown in Figure 7. It is observed that manganese has a higher vapor pressure than nickel, which means that manganese evaporates 
much easier than nickel. This suggests that the manganese impurity can be readily removed from liquid nickel during HPAM. Compared to the atmospheric pressure conditions, the vaporization of manganese is enhanced under low pressure, because of the higher activity coefficient of manganese in the nickel melt at negative pressure $[18,24]$. Therefore, a low melting pressure is an important factor for removing manganese from liquid nickel.

$$
\begin{gathered}
M n: \lg P=5.006+12.805-15097 / T-1.7896 \lg T(298 K-\text { m.p. }) \\
\begin{array}{c}
N i: \lg P=5.006+10.557-22606 / T-0.8717 \lg T(298 K-\text { m.p. }) \\
\lg P=5.006+6.666-20765 / T(\text { m.p. }-2150 K)
\end{array}
\end{gathered}
$$

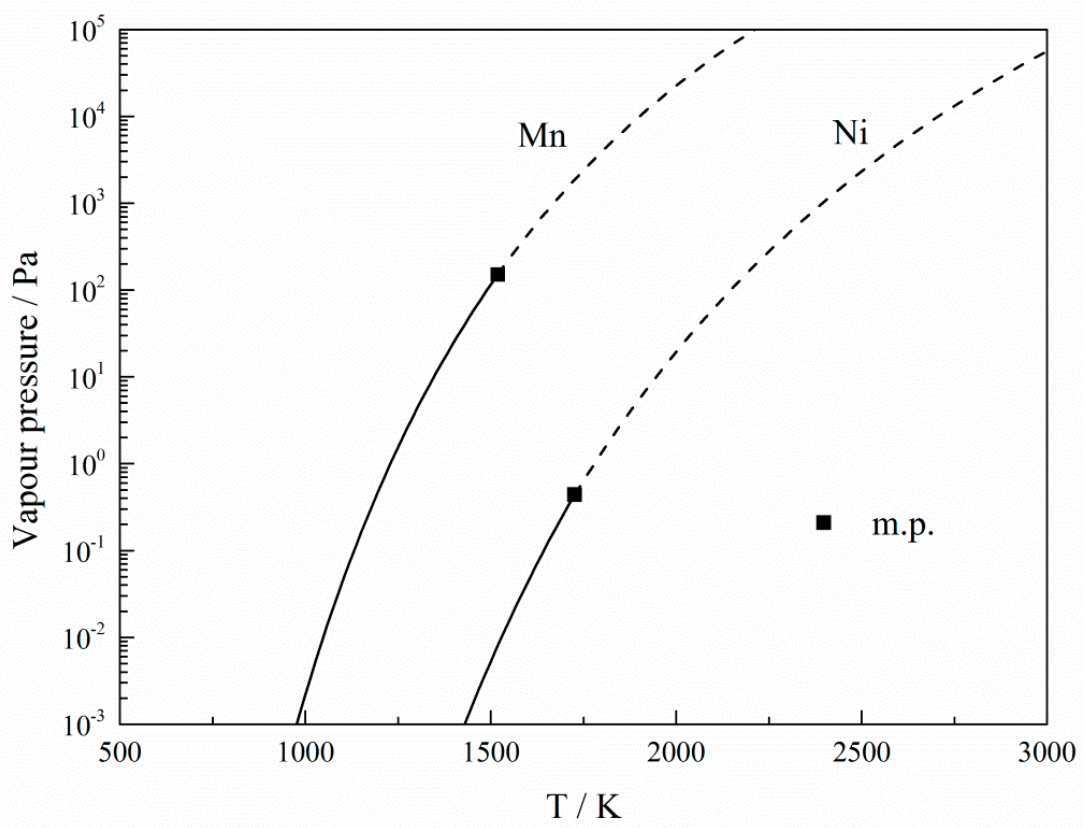

Figure 7. Vapor pressures of manganese impurity and nickel metal as a function of temperature.

Addition of hydrogen to plasma gas is another important way to enhance the removal of manganese. Figure 8 shows a schematic diagram of the manganese removal process during HPAM, and the process can be expressed by Equation (8). As shown in Figure 8, the evaporated manganese $\left(M n_{\text {vap }}\right)$ reacts with active hydrogen atoms to form manganese hydrides $\left(M n \cdot H_{x}\right)$ that would dissociate to manganese and hydrogen at low temperatures. In other words, the metal vapor within the gaseous boundary was enhanced by the dynamic interaction between the hydrogen atoms and the metal vapor [25]. Therefore, the manganese content reduction rate can be noticeably increased even under atmospheric pressure when hydrogen was added to plasma gas. Approximately 95\% of the hydrogen molecules dissociated to hydrogen atoms under the high electric field from the transferred arc power at $5000 \mathrm{~K}$ [26]. That is to say, the hydrogen molecules dissociate to atoms in the plasma arc when hydrogen is added to the plasma gas. Due to the high thermal conductivity of the activated hydrogen atoms, the heat capacity and heat conductivity of the plasma are enhanced by the adding hydrogen compared to the case when the plasma gas consisted of argon only. As a result, the temperature of the nickel melt increases when the active hydrogen atoms were dissolved in the liquid nickel. It is observed from Figure 8 that the increasing temperature can improve the vapor pressure of manganese. This indicates that elevating the temperature by adding hydrogen to plasma gas enhances the removal of 
manganese from the nickel melt. Furthermore, the reaction described in Equation (8) is also accelerated at elevating temperature.

$$
M n(v a p)+x H \rightarrow M n \cdot H_{x} \rightarrow M n+x / 2 H_{2}
$$

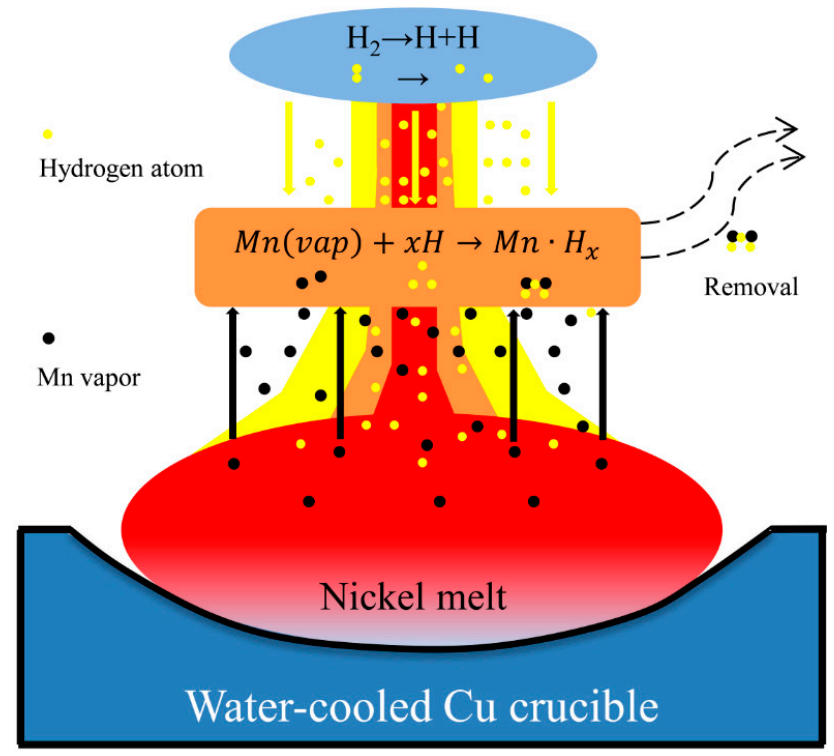

Figure 8. Schematic diagram of manganese removal from nickel melt during HPAM.

\section{Conclusions}

In the present study, removal of manganese from nickel melt by HPAM is studied systematically. The concentration of manganese in liquid nickel decreases slowly with melting time when the plasma gas consists of argon only. However, the manganese content decreases noticeably upon the addition of hydrogen to the plasma gas. Moreover, the rate of manganese removal increases with the reduction in the pressure. Kinetic analyses suggest that the process of manganese removal from liquid nickel by HPAM obeys the first-order kinetics rate law. The manganese content reduction rate increases proportionally with approximately $0.73-0.75$ th powers of the hydrogen volume fraction in the plasma gas. The hydrogen volume fraction exponent increases to 0.88 th when the initial manganese content increases from 0.45 mass $\%$ to 0.89 mass $\%$. The thermodynamic results indicate that the low pressure and high temperature of the melt promote the volatilization of manganese from liquid nickel. The dissociation of the hydrogen molecules to active hydrogen atoms improves the temperature of the melt due to the high heat conductivity of the active hydrogen atoms.

Author Contributions: X.G. conceived and designed the experiment; X.G., J.Y., Y.H. and Y.Z. performed the experiments; X.G., J.Y., Y.H., Y.Z., J.W., X.L., H.L. and Z.R. contributed to analyzing the data and to write the paper.

Funding: This work was financially supported by the Ministry of Science and Technology [2017YFB0405902], the Natural Science Foundation of China [No. U1560202, 51604171, 51690162] and the Shanghai Municipal Science and Technology Commission [No.17JC1400602].

Conflicts of Interest: The authors declare no conflict of interest.

\section{References}

1. Waseda, Y.; Isshiki, M. Purification Process and Characterization of Ultra High Purity Metals: Application of Basic Science to Metallurgical Processing; Springer Science \& Business Media: Berlin, Germany, 2012.

2. Shi, L.; Sun, C.; Gao, P.; Zhou, F.; Liu, W. Mechanical properties and wear and corrosion resistance of electrodeposited Ni-Co/SiC nanocomposite coating. Appl. Surface Sci. 2006, 252, 3591-3599. [CrossRef] 
3. Lü, X.; Bao, X.; Huang, Y.; Qu, Y.; Lu, H.; Lu, Z. Mechanisms of cytotoxicity of nickel ions based on gene expression profiles. Biomaterials 2009, 30, 141-148. [CrossRef] [PubMed]

4. French, B.J. Nickel-Base Alloys Having a Low Coefficient of Thermal Expansion. Google Patents 11 November 1975.

5. Birol, Y. Ni-based superalloy as a potential tool material for thixoforming of steels. Ironmak. Steelmak. 2009, 36, 555-560. [CrossRef]

6. Liu, B.H.; Li, Z.P.; Suda, S. Nickel-and cobalt-based catalysts for hydrogen generation by hydrolysis of borohydride. J. Alloys Compd. 2006, 415, 288-293. [CrossRef]

7. Ishii, F.; Ban-Ya, S. Deoxidation Equilibrium of Silicon in Liquid Nickel-Chromium, Nickel-Molybdenum and Nickel-Tungsten Alloys. ISIJ Int. 1992, 32, 1097-1101. [CrossRef]

8. Ban-Ya, S.; Ishii, F.; Ohtaki, D. Deoxidation Equilibrium of Hafnium in Liquid Iron, Nickel and Iron-Nickel Alloys. ISIJ Int. 1994, 34, 484-490. [CrossRef]

9. Ishii, F.; Ban-Ya, S. Equilibrium between Yttrium and Oxygen in Liquid Iron and Nickel. ISIJ Int. 1995, 35, 280-285. [CrossRef]

10. Ishii, F.; Ban-Ya, S.; Hino, M. Thermodynamics of the Deoxidation Equilibrium of Aluminum in Liquid Nickel and Nickel-Iron Alloys. ISIJ Int. 1996, 36, 25-31. [CrossRef]

11. Yonemoto, L.M.; Miki, T.; Hino, M. Magnesium Deoxidation Equilibrium of Molten Fe-Ni Alloy Expressed by Quadratic Formalism and Redlich-Kister Type Polynomial. ISIJ Int. 2008, 48, 755-759. [CrossRef]

12. Dashevskiy, V.Y.; Aleksandrov, A.A.; Kanevskiy, A.G.; Leont'ev, L.I. Deoxidation Equilibrium of Zirconium in the Iron-Nickel Melts. ISIJ Int. 2013, 53, 1120-1124. [CrossRef]

13. Zhang, T.; Shang, Z.; Chen, M.; He, J.; Lv, B.; Wang, X.; Xiong, X. High-Purity Nickel Prepared by Electron Beam Melting: Purification Mechanism. Metall. Mater. Trans. B 2014, 45, 164-174. [CrossRef]

14. Oh, J.M.; Roh, K.M.; Lim, J.W. Brief review of removal effect of hydrogen-plasma arc melting on refining of pure titanium and titanium alloys. Int. J. Hydrog. Energy 2016, 41, 23033-23041. [CrossRef]

15. Su, Y.; Liu, X.; Luo, L.; Zhao, L.; Guo, J.; Fu, H. Deoxidation of Ti-Al Intermetallics via Hydrogen Treatment. Int. J. Hydrog. Energy 2010, 35, 9214-9217. [CrossRef]

16. Elanski, D.; Lim, J.W.; Mimura, K.; Isshiki, M. Impurity removal from Zr, Nb and Ta metals by hydrogen plasma arc melting and thermodynamic estimation of hydride formation. J. Alloys Compd. 2006, 413, 251-258. [CrossRef]

17. Mimura, K.; Kornukai, T.; Isshiki, M. Purification of chromium by hydrogen plasma-arc zone melting. Mater. Sci. Eng. A 2005, 403, 11-16. [CrossRef]

18. Mimura, K.; Matsumoto, K.; Isshiki, M. Purification of Hafnium by Hydrogen Plasma Arc Melting. Mater. Trans. 2011, 52, 159-165. [CrossRef]

19. Li, G.; Li, L.; Yang, C.; Tian, W.; Li, X. Removal of gaseous impurities from terbium by hydrogen plasma arc melting. Int. J. Hydrog. Energy 2015, 40, 7943-7948. [CrossRef]

20. Elanski, D.; Lim, J.W.; Mimura, K.; Isshiki, M. Impurity removal from Fe, Cr, Ti, and V metals by hydrogen plasma arc melting and thermodynamic estimation of hydride and sulfide formation. J. Alloys Compd. 2006, 421, 209-216. [CrossRef]

21. Jung-Min, O.; Back-Kyu, L.; Chang-Youl, S.; Jae-Won, L. Removal of metallic impurities from Ti binary alloy scraps using hydrogen plasma arc melting. J. Alloys Compd. 2013, 574, 1-5.

22. Li, G.; Li, L.; Fu, K.; Wang, C.; Zheng, J.; Xu, L.; Tian, W.; Li, X. Hydrogen in-situ refining method for preparing high purity gadolinium. J. Alloys Compd. 2015, 648, 29-33. [CrossRef]

23. Lide, D.R. CRC Handbook of Chemistry and Physics; CRC Press: Boca Raton, FL, USA, 2004.

24. Fromm, E. Reduction of Metal Evaporation Losses by Inert Gas Atmospheres. Metall. Trans. A 1978, 9 , 1835-1838. [CrossRef]

25. Mimura, K.; Lee, S.; Isshiki, M. Removal of alloying elements from zirconium alloys by hydrogen plasma-arc melting. J. Alloys Compd. 1995, 221, 267-273. [CrossRef]

26. Dembovský, V. Plasma Metallurgy: The Principles; Butterworth-Heinemann Limited: Amsterdam, The Netherlands, 1985.

(C) 2018 by the authors. Licensee MDPI, Basel, Switzerland. This article is an open access article distributed under the terms and conditions of the Creative Commons Attribution (CC BY) license (http:/ / creativecommons.org/licenses/by/4.0/). 